\title{
Protocol
}

\section{Mind-Body Therapies for Cancer Patients Living with Depression, Anxiety or Insomnia (MIRACLE): A Systematic Review with Individual Participant Data Network Meta-Analysis}

\author{
Yoann Birling ${ }^{1, *}$, Sarah Nevitt ${ }^{2}$, Deep Jyoti Bhuyan ${ }^{1, * \mathbb{C}}$, Mingxian Jia ${ }^{3}$, Fan Feng ${ }^{4}$, Linda Ellen Carlson ${ }^{5}$, \\ Tiffany Pham ${ }^{6}$, Jing Liu ${ }^{6}\left(\mathbb{D}\right.$, Zahra Ayati ${ }^{1}$, Liyi Nyiam ${ }^{7}$, Zhichao Yu ${ }^{6,8}$ and Paul Fahey ${ }^{6}(\mathbb{D}$
}

Citation: Birling, Y.; Nevitt, S.; Bhuyan, D.J.; Jia, M.; Feng, F.; Carlson, L.E.; Pham, T.; Liu, J.; Ayati, Z.; Nyiam, L.; et al. Mind-Body Therapies for Cancer Patients Living with Depression, Anxiety or Insomnia (MIRACLE): A Systematic Review with Individual Participant Data Network Meta-Analysis. Methods Protoc. 2021, 4, 76. https:// doi.org/10.3390/mps4040076

Academic Editor: Philip Hublitz

Received: 17 August 2021

Accepted: 13 October 2021

Published: 19 October 2021

Publisher's Note: MDPI stays neutral with regard to jurisdictional claims in published maps and institutional affiliations.

Copyright: (C) 2021 by the authors Licensee MDPI, Basel, Switzerland. This article is an open access article distributed under the terms and conditions of the Creative Commons Attribution (CC BY) license (https:/ / creativecommons.org/licenses/by/ $4.0 /)$.
1 NICM Health Research Institute, Western Sydney University, Penrith 2751, Australia; Z.Ayati@westernsydney.edu.au

2 Institute of Population Health, University of Liverpool, Liverpool L69 3GF, UK; Sarah.Nevitt@liverpool.ac.uk

3 Institute of Chinese Medicine, China Resources Sanjiu Medical and Pharmaceutical Co., Ltd., Shenzhen 518110, China; mingxian.jia@hotmail.com

4 Benson Henry Institute for Mind Body Medicine, Massachusetts General Hospital, Boston, MA 02114, USA; FFENG1@mgh.harvard.edu

5 Department of Psychology, University of Calgary, Calgary, AB T2N 1N4, Canada; 1.carlson@ucalgary.ca

6 School of Health Sciences, Western Sydney University, Penrith 2751, Australia; 17119245@student.westernsydney.edu.au (T.P.); 19640192@student.westernsydney.edu.au (J.L.); zhichao.yu@westernsydney.edu.au (Z.Y.); p.fahey@westernsydney.edu.au (P.F.)

7 Pre-Disease Treatment Department, The Gulou Hospital of Traditional Chinese Medicine of Beijing, Beijing 100009, China; wanzhi_hino@yahoo.com

8 The First Clinical Medical College, Nanjing University of Chinese Medicine, Nanjing 210023, China

* Correspondence: y.birling@westernsydney.edu.au (Y.B.); d.bhuyan@westernsydney.edu.au (D.J.B.)

Abstract: Depression, anxiety, and insomnia are common in cancer patients. Mind-body therapies (MBTs) are promising forms of treatment for cancer patients living with depression, anxiety, and insomnia. The objective of this study is to assess the effectiveness and acceptability of MBTs in cancer patients living with depression, anxiety, or insomnia. EMBase, PubMed, Cinahl, PsychINFO, IndMED, CSI-NISCAIR, CNKI, Clinicaltrial.gov, ChiCTR, and CTRI will be searched until October 2020 for relevant studies. Randomized controlled studies in which MBTs were tested in a cancer population will be selected. The authors of the selected studies will be contacted to obtain individual participant data. The participants who reached a defined clinical threshold for depression, anxiety, or insomnia will be selected for the three sub-studies on depression, anxiety, and insomnia, respectively. Pairwise and network meta-analyses will be used to assess the changes in depression, anxiety, sleep quality, and completion rate. We will assess the effect of the treatment dose (number and frequency of interventions) on effectiveness. The results of this study will inform clinical decision-making for the treatment of psychological disturbances in cancer patients. If MBTs are found effective, they will potentially be recommended as treatments for cancer patients with psychological symptoms.

Keywords: cancer; depression; anxiety; insomnia; yoga; tai chi; qigong; relaxation; mind-body; mindfulness

\section{Background}

Psychological disturbances are highly prevalent in cancer patients. It is estimated that approximately $25 \%, 10 \%$, and $28 \%$ of cancer patients suffer from clinical depression, anxiety, and insomnia, respectively [1,2], which is roughly double the rates of the general population [3-6]. This higher prevalence can be attributed to the shock caused by a cancer diagnosis [7], the burden of cancer treatment [8], and the correlations between different psychological symptoms and between these symptoms and fatigue and pain [9-14]. In this 
context, treatments targeting different aspects of physical and psychological health have a decisive advantage in the treatment of psychological disturbances in cancer patients.

Depression, anxiety, and insomnia significantly impair the quality of life of cancer patients. Psychological health strongly predicts quality of life in cancer patients [15] and impacts treatment outcomes [16-18]. Moreover, the hyperactivity of the hypothalamuspituitary axis (HPA) present in psychological disturbances weakens the immune system, affecting its ability to fight cancer [19]. For the above reasons, psychological disturbances increase mortality in cancer patients $[20,21]$. The effective management of psychological symptoms improves both adherence to anti-cancer treatment and mortality rates [22-24].

Psychological disturbances in cancer patients are mostly treated with pharmacological drugs, such as hypnotics, antidepressants, and anxiolytics [25,26]. Although the efficacy of these treatments has been proven, they tend to induce adverse reactions, such as morning sedation, anterograde amnesia, falls, undesired sleep behavior, gastrointestinal symptoms, weight gain, sexual dysfunction, and anxiety [27-32]. Moreover, long-term use of psychotropic medications increases the risk of dementia, diabetes, and cancer, and increases the overall mortality rates [33-39]. Patients who suffer from psychological disturbances prefer non-pharmacological approaches [40,41].

Mind-body therapies (MBTs) are practices that aim to improve health through mindfulness, breathing exercises, postures, movements, and relaxation [42,43]. They include ancient practices, such as yoga, qi gong, and tai chi, and modern therapies, such as mindfulness-based stress reduction (MBSR) training and progressive muscular relaxation (PMR). Due to their broad effect on well-being, including improved mood, reduced pain, higher energy levels, and higher social functioning, MBTs seem to be ideal treatment approaches for psychological disturbances in cancer patients [44-50]. They are also relatively safe and widely accessible to cancer patients in many parts of the world.

Previous systematic reviews have shown that MBTs can improve the moods and sleep quality levels of cancer patients [51-56]. However, these reviews included both participants living with and not living with psychological disturbances. They did not report the acceptability of the interventions, which is an important aspect to consider in decision-making, as cancer patients have limited time and energy. They did not report either the treatment dose (number and frequency of treatments) necessary to achieve clinically significant improvements. Thus, a review of the effectiveness and acceptability of MBTs in cancer patients living with depression, anxiety, or insomnia is needed.

Most randomized-controlled trials testing MBTs for cancer patients have not specifically selected cancer patients living with psychological disturbances [57]. Therefore, it is crucial to collect the individual participant data (IPD) from these RCTs and conduct a meta-analysis with the data from participants who meet the clinical thresholds for depression, anxiety, and/or insomnia. Different MBTs are rarely compared to each other in clinical trials; therefore, a network meta-analysis (NMA) is necessary to assess the relative effectiveness of different MBTs.

\section{Methods}

This study will be conducted according to the Cochrane guidelines on IPD systematic reviews and NMA systematic reviews [58,59]. The protocol was registered in PROSPERO (CRD42021240595). The results of this review will be published separately for each of the sub-studies. The Human Research Ethics Committee of Western Sydney University, Australia exempted the present review from ethical review. The methodological processes of the study are reported in Figure 1. 




Figure 1. Methodological processes of the systematic review.

\subsection{Study Selection}

\subsubsection{Study Design}

Studies in which participants were randomly allocated will be included. Both parallel and cross-over studies will be included. For cross-over studies, only the first period of the study will be included.

\subsubsection{Participants}

We will include adults diagnosed with cancer-regardless of the type of cancer, cancer stage, type of treatment received, or stage of treatment. However, studies conducted specifically around a medical procedure (e.g., biopsy, surgery) will be excluded.

For the sub-study on depression, we will select the participants who meet the clinical threshold for depression on a validated tool. The accepted assessment tools with validated cut-off scores are: (1) PHQ-9 score $\geq 10$ [60]; (2) CES-D score $\geq 20$ [61]; (3) BDI score $\geq 16$ [62]; (4) HAMD score $\geq 12$ [63]; (5) POMS depression score $\geq 7$ [64]; (6) PHQ-2 score $\geq 2$ [60]; (7) HADS-D $\geq 11$ [65]; (8) PROMIS depression scale score $\geq 8$ [66]; (9) DASS-D score $\geq 10$ [67]; (10) SCL-90 depression score $\geq 25$ [63]; (11) MADRS score $\geq 12$ [68]; and (12) BDI-II score $\geq 14$ [69]. If the participant was assessed with two of these tools, the decision will be based on one assessment tool, in the above order of priority.

For the sub-study on anxiety, we will select the participants who meet the clinical threshold for anxiety on a validated tool. The accepted assessment tools with validated cutoff scores are: (1) GAD-7 score $\geq 8$ [70]; (2) HAMA score $\geq 11$ [71]; (3) BAI score $\geq 12$ [72]; (4) HADS-A $\geq 11$ [65]; (5) STAI-S $\geq 51$ [73]; STAI-T $\geq 53$ [73]; (6) DASS-A $\geq 8$ [67]; (7) PROMIS anxiety score $\geq 8$ [66]; (8) GAD-2 $\geq 3$ [70]; (9) POMS anxiety score $\geq 16$ [74]; 
and (10) PSWQ $\geq 62$ [75]. If the participant was assessed with two of these tools, the decision will be based on one assessment tool, in the above order of priority.

For the sub-study on insomnia, we will select the participants who meet the clinical threshold for insomnia on a validated tool. The acceptable assessment tools with validated cut-off scores are: (1) ISI score $\geq 11$ [76]; (2) PSQI score $\geq 6$ [77]; and (3) AISI score $\geq 6$ [78]. If the participant was assessed with two of these tools, the decision will be based on one assessment tool, in the above order of priority.

\subsubsection{Interventions}

MBTs are defined as therapies that emphasize the use of the brain in conjunction with the body to assist the healing process [79]. Meditation, mindfulness-based therapies, mindfulness-based cognitive therapy, yoga-based interventions, tai chi, qigong, visualization and imagery, hypnosis and self-suggestion, art therapy, music therapy, dance therapy, biofeedback, and relaxation training-including compound interventions of the above-will be included in this review. Psychotherapy, exercise therapy, and acupuncture will not be accepted. Compound interventions, including MBT and counseling, education, and/or diet, will not be accepted except in cases where the non-MBT interventions are minor. In the NMA, the interventions will be grouped by label (e.g., "yoga", "qigong") rather than treatment components (e.g., breathing techniques, mindfulness). For example, two interventions respectively labeled "yoga" and "qigong" by the study authors but involving the same components (e.g., breathing techniques and posture) will be grouped under two different categories.

\subsubsection{Controls}

Inactive controls and active controls, such as wait-list, no-treatment, usual care, exercise therapy, psychoeducation, sham MBT, or another MBT, will be considered as appropriate control interventions.

\subsubsection{Outcomes}

For each sub-study, the primary outcomes will be, respectively, depression severity, anxiety severity, and insomnia severity, assessed with a validated questionnaire. The secondary outcome is acceptability, represented by the completion rate.

\subsection{Search Strategy}

The search terms are constructed around four themes (i.e., "mental health", "cancer", "mind-body therapies", and "randomized controlled trial") using both medical heading $(\mathrm{MeSH})$ terms and text words. The theme "mental health" covers insomnia, depression, and anxiety. The Boolean operator "OR" will be used between search terms within each theme, and the Boolean operator "AND" will be used between search themes. No language restriction will be applied to the search. The literature search will be updated after data collection (including the IPD requests) is completed.

The following databases will be searched until October 2020 (see the full strategy in Appendix A): EMBase, PubMed, Cinahl, Cochrane Library, PsychINFO, IndMED, CSIRNISCAIR, CNKI, Clinicaltrial.gov, ChiCTR, and CTRI.

Previous reviews will be hand-searched for additional studies and a forward search (i.e., the search of publications that cited the included articles) will be conducted using PubMed. The authors of the included studies will be asked about recent unpublished studies when contacted to request the IPD.

\subsection{Screening}

The studies will be screened by five teams of two reviewers working independently. The results of the screening will be compared between the two reviewers of each team. The first step will be the title/abstract screening. Then the full text of each reference will be downloaded. Finally, the full text will be screened. Disagreements will be resolved 
through discussion and then through the decision of a third reviewer if consensus cannot be reached. In the case of significant discrepancies, the screening criteria will be revised, and the screening will be conducted again from the beginning.

\subsection{Data Extraction}

The data from the included studies will be extracted by four teams of two reviewers working independently. We will use a standardized data collection spreadsheet for data extraction. We will resolve any disagreements on data extraction through discussion or by consulting a third reviewer, if necessary. The data collection form includes the following items:

- List of authors and contact details

- Year of publication

- Treatment arms with sample size (intention-to-treat)

- Selection of participants according to insomnia, anxiety, or depression diagnosis and diagnostic tool

- Participant characteristics (gender, age, type and stage of cancer, type and stage of anticancer treatment)

- Intervention details (intervention name, treatment frequency and duration, session duration, mode of delivery, presence of home practice) for both experimental and control groups

- Outcome measures

- $\quad$ Outcome at baseline, during treatment, and at post-treatment

\subsection{Data Request}

We will contact the corresponding author of the included studies via email for clarifications. If the corresponding author is not available, we will contact the other authors of the study. If there is no outcome from the email approach, we will contact the authors via phone and social media platforms. We will ask the data provider to remove any identifiable data, such as names, addresses, and/or phone numbers, from the dataset before providing the data. The requested data include the following items:

- Participant covariates (gender, age, type and stage of cancer, type and stage of anticancer treatment, presence and type of psychotropic treatment)

- All relevant outcomes for any time point

- Adherence to treatment (number of sessions completed)

- Completion status, with the withdrawal time point and reason in the case of non-completion

For each trial where IPD were supplied, we will reproduce results from trial findings, where possible, and cross-check the data against any published report of the trial. Any inconsistencies will be discussed with the corresponding data providers.

\subsection{Data Management and Preparation}

The data will be stored in a password-protected excel file that is only accessible by the individual responsible for the study (YB) and the statistician (PF). The data will be standardized and collated by YB.

\subsection{Risk of Bias Assessment}

The risk of bias will be assessed by four teams of two reviewers working independently with version two of the Cochrane Collaboration's Risk of Bias assessment tool [80]. The risk of bias, in terms of the randomization process, deviations from intended interventions, missing outcome data, measurement of the outcomes, selection of the reported results, and overall bias, is judged using the categories of "low", "some concerns", or "high". The risk of bias will be assessed for the primary outcome of the study. In case the information from the report(s) is not sufficient to reach a judgment about the risk of bias, the author 
of the study will be contacted for clarifications. Disagreements will be resolved through discussion and consulting a third team member reviewer.

\subsection{Publication Bias Assessment}

We will assess potential publication bias with a funnel plot for the whole NMA [81]. The Egger test [82] and the Begg test [83] will also be used to evaluate publication bias.

\subsection{Heterogeneity and Consistency Assessment}

The heterogeneity of the included studies will be presented with the I2 statistic, with values of $50 \%$ or more considered to be indicators of a substantial level of heterogeneity [59]. In the case of a high level of heterogeneity, the reason for the heterogeneity (e.g., participant type, intervention type, or duration) will be investigated. Sensitivity analyses will be conducted to determine the impact of these factors on the results of the studies.

In order to comply with the transitivity assumption, only trials in which the interventions could be "jointly randomizable" [84] will be included in the NMA. Inconsistency between direct and indirect sources of evidence will be statistically assessed globally (through the comparison of the fit and parsimony of the consistency and inconsistency models) and locally (through the calculation of the differences between direct and indirect estimates in all closed loops in the network).

\subsection{Pairwise and Network Meta-Analyses}

Traditional meta-analyses will be conducted in cases where several studies have used the same control intervention and the same outcome. Where all studies used the same measurement tool, the results will be combined as mean differences with a $95 \% \mathrm{CI}$ (for continuous data) and odds ratios with a $95 \% \mathrm{CI}$ (for dichotomous data). Where studies used different measurement tools, the results will be combined as standardized mean differences (SMDs) with a 95\% CI (for continuous data) and odds ratios with a 95\% CI (for dichotomous data). A random-effects model will be used for the analysis.

In order to rank the effectiveness of each MBT, an NMA will be conducted. This NMA will include direct and indirect comparisons between different MBTs. The NMA will be adjusted for the presence of multi-arm trials. A network plot will be used to describe the geometry of the treatment network. SMDs with a 95\% CI will be used as summary measures. To rank the treatments for each outcome, the surface under the cumulative ranking (SUCRA) probabilities will be used.

All tests will be 2-tailed, and a $p$-value of less than 0.05 will be considered statistically significant. Statistical analyses will be performed using $R$ and/or Stata statistical packages.

\subsection{Subgroup and Sensitivity Analyses}

We will conduct meta-regressions to assess the influence of the following factors on the primary outcomes:

- Cancer site

- $\quad$ Cancer stage, separating early stages (stages 0 and I) and late stages (stages II, III, and IV)

- Presence or absence of concomitant anti-cancer treatment

- Concomitant usage of psychotropic treatment

- Presence or absence of home practice

- Gender

If there is sufficient data, we will conduct sensitivity analyses with the following studies:

- Only studies in which the overall risk of bias was low

- Studies in which the IPD was available and studies in which the IPD was not available (the aggregated mean from the reports will be compared)

- Studies in which mental disorders were diagnosed according to a recognized diagnostic standard 


\section{Discussion}

This is the first systematic review in which data from clinical trials testing MBTs for cancer patients is selected according to cut-off scores in psychological scales. This will allow us to provide conclusions about the usefulness of MBTs for cancer patients living with depression, anxiety, and insomnia. The NMA will show the relative effectiveness and acceptability of different MBTs. We will discuss the potential mechanism of MBTs in the discussion section of the future report. The results of this systematic review may have a significant influence on future clinical guidelines and clinical practice. It will inform clinicians about the effectiveness and acceptability of MBTs, thus helping them select the most appropriate intervention for their patients, as well as the treatment dose necessary, to achieve clinically significant changes.

Author Contributions: Conceptualization, Y.B.; methodology, Y.B., S.N., and P.F.; writing—original draft preparation, Y.B.; writing-review and editing, S.N., D.J.B., M.J., F.F., L.E.C., T.P., J.L., Z.A., L.N., Z.Y. and P.F. All authors have read and agreed to the published version of the manuscript.

Funding: This research received no external funding.

Institutional Review Board Statement: Ethical review and approval were waived for this study, due to the study being a review of existing data.

Informed Consent Statement: No applicable.

Data Availability Statement: Not applicable.

Acknowledgments: We would like to acknowledge the help and support of Katrina Chaudhary, Diana Karamacoska, Maria Gonzalez, Michael de Manincor, Youmi Park, James Lake, Emily Yang, Xiaoshu Zhu, and Alan Bensoussan.

Conflicts of Interest: As a medical research institute, the NICM Health Research Institute (NICM HRI) receives grants and donations from foundations, universities, government agencies, individuals, and industry. Sponsors and donors also provide untied funding to advance the vision and mission of the NICM HRI. The authors declare no conflict of interest.

\section{Appendix A}

PubMed search (with the filters "Clinical Trial" and "Randomized Controlled Trial" applied).

\#1. "mind-body therapies"[MeSH Terms] OR "mind body therap*"[Title/Abstract] OR "yoga"[MeSH Terms] OR "qigong"[MeSH Terms] OR "tai ji"[MeSH Terms] OR "mindfulness"[MeSH Terms] OR "meditation"[MeSH Terms] OR "yoga"[Title/Abstract] OR "qigong"[Title/Abstract] OR "qi gong"[Title/Abstract] OR "taiji"[Title/Abstract] OR “taichi"[Title/Abstract] OR “tai ji" [Title/Abstract] OR "tai chi”"[Title/Abstract] OR "mindfulness"[Title/Abstract] OR "relaxation"[Title/Abstract] OR "meditation"[Title/Abstract].

\#2. "neoplasms"[MeSH Terms] OR "cancer survivors"[MeSH Terms] OR "neoplasms" [Title/Abstract] OR "tumor"[Title/Abstract] OR "cancer"[Title/Abstract] OR "leukemia" [Title/Abstract] OR "myeloma"[Title/Abstract] OR "lymphoma"[Title/Abstract].

\#3. "sleep initiation and maintenance disorders"[MeSH Terms] OR "insomnia" [Title/Abstract] OR "sleeplessness"[Title/Abstract] OR "sleep disturbances"[Title/Abstract] OR "sleep" [Title/Abstract] OR "depressive disorder"[MeSH Terms] OR "depression"[MeSH Terms] OR “depressive disorder" [MeSH Terms] OR “depressive disorder, major" [MeSH Terms] OR "dysthymic disorder"[MeSH Terms] OR "adjustment disorders"[MeSH Terms] OR "depression"[Title/Abstract] OR "mood"[Title/Abstract] OR "anxiety"[MeSH Terms] OR "anxiety"[Title/Abstract] OR "anxiety disorders"[Title/Abstract] OR "phobic disorders" [MeSH Terms] OR "mental health" [MeSH Terms] OR "mental disorders"[MeSH Terms] OR "psycholog*"[Title/Abstract].

\#4. \#1 AND \#2 AND \#3. 


\section{References}

1. Savard, J.; Ivers, H.; Villa, J.; Caplette-Gingras, A.; Morin, C.M. Natural course of insomnia comorbid with cancer: An 18-month longitudinal study. J. Clin. Oncol. 2011, 29, 3580-3586. [CrossRef]

2. Mitchell, A.J.; Chan, M.; Bhatti, H.; Halton, M.; Grassi, L.; Johansen, C.; Meader, N. Prevalence of depression, anxiety, and adjustment disorder in oncological, haematological, and palliative-care settings: A meta-analysis of 94 interview-based studies. Lancet Oncol. 2011, 12, 160-174. [CrossRef]

3. Cao, X.-L.; Wang, S.-B.; Zhong, B.-L.; Zhang, L.; Ungvari, G.S.; Ng, C.H.; Li, L.; Chiu, H.F.; Lok, G.K.; Lu, J.-P. The prevalence of insomnia in the general population in China: A meta-analysis. PLoS ONE 2017, 12, e0170772. [CrossRef] [PubMed]

4. Morin, C.M.; LeBlanc, M.; Bélanger, L.; Ivers, H.; Mérette, C.; Savard, J. Prevalence of insomnia and its treatment in Canada. Can. J. Psychiatry 2011, 56, 540-548. [CrossRef]

5. Lim, G.Y.; Tam, W.W.; Lu, Y.; Ho, C.S.; Zhang, M.W.; Ho, R.C. Prevalence of depression in the community from 30 countries between 1994 and 2014. Sci. Rep. 2018, 8, 1-10. [CrossRef] [PubMed]

6. Baxter, A.J.; Scott, K.; Vos, T.; Whiteford, H. Global prevalence of anxiety disorders: A systematic review and meta-regression. Psychol. Med. 2013, 43, 897. [CrossRef]

7. Schag, C.; Ganz, P.A.; Polinsky, M.L.; Fred, C.; Hirji, K.; Petersen, L. Characteristics of women at risk for psychosocial distress in the year after breast cancer. J. Clin. Oncol. 1993, 11, 783-793. [CrossRef]

8. Fann, J.R.; Fan, M.-Y.; Unützer, J. Improving primary care for older adults with cancer and depression. J. Gen. Intern. Med. 2009, 24, 417-424. [CrossRef]

9. Neckelmann, D.; Mykletun, A.; Dahl, A.A. Chronic insomnia as a risk factor for developing anxiety and depression. Sleep 2007, 30, 873-880. [CrossRef]

10. Johnson, E.O.; Roth, T.; Breslau, N. The association of insomnia with anxiety disorders and depression: Exploration of the direction of risk. J. Psychiatr. Res. 2006, 40, 700-708. [CrossRef]

11. Jansson-Fröjmark, M.; Lindblom, K. A bidirectional relationship between anxiety and depression, and insomnia? A prospective study in the general population. J. Psychosom. Res. 2008, 64, 443-449. [CrossRef]

12. Redeker, N.S.; Lev, E.L.; Ruggiero, J. Insomnia, fatigue, anxiety, depression, and quality of life of cancer patients undergoing chemotherapy. Sch. Inq. Nurs. Pract. 2000, 14, 275-290.

13. Chen, M.-L.; Tseng, H.-C. Symptom clusters in cancer patients. Support. Care Cancer 2006, 14, 825-830. [CrossRef]

14. Hoang, H.T.X.; Molassiotis, A.; Chan, C.W.; Nguyen, T.H. New-onset insomnia among cancer patients undergoing chemotherapy: Prevalence, risk factors, and its correlation with other symptoms. Sleep Breath. 2020, 24, 241-251. [CrossRef]

15. Dong, S.T.; Costa, D.S.; Butow, P.N.; Lovell, M.R.; Agar, M.; Velikova, G.; Teckle, P.; Tong, A.; Tebbutt, N.C.; Clarke, S.J. Symptom clusters in advanced cancer patients: An empirical comparison of statistical methods and the impact on quality of life. J. Pain Symptom Manag. 2016, 51, 88-98. [CrossRef] [PubMed]

16. Arrieta, Ó.; Angulo, L.P.; Núñez-Valencia, C.; Dorantes-Gallareta, Y.; Macedo, E.O.; Martínez-López, D.; Alvarado, S.; CoronaCruz, J.-F.; Oñate-Ocaña, L.F. Association of depression and anxiety on quality of life, treatment adherence, and prognosis in patients with advanced non-small cell lung cancer. Ann. Surg. Oncol. 2013, 20, 1941-1948. [CrossRef]

17. Mausbach, B.T.; Schwab, R.B.; Irwin, S.A. Depression as a predictor of adherence to adjuvant endocrine therapy (AET) in women with breast cancer: A systematic review and meta-analysis. Breast Cancer Res. Treat. 2015, 152, 239-246. [CrossRef] [PubMed]

18. DiMatteo, M.R.; Haskard-Zolnierek, K.B. Impact of depression on treatment adherence and survival from cancer. Depress. Cancer 2011, 101-124.

19. Glaser, R.; Kiecolt-Glaser, J.K. Stress-induced immune dysfunction: Implications for health. Nat. Rev. Immunol. $2005,5,243-251$. [CrossRef] [PubMed]

20. Pinquart, M.; Duberstein, P. Depression and cancer mortality: A meta-analysis. Psychol. Med. 2010, 40, 1797-1810. [CrossRef]

21. Wang, Y.-H.; Li, J.-Q.; Shi, J.-F.; Que, J.-Y.; Liu, J.-J.; Lappin, J.M.; Leung, J.; Ravindran, A.V.; Chen, W.-Q.; Qiao, Y.-L. Depression and anxiety in relation to cancer incidence and mortality: A systematic review and meta-analysis of cohort studies. Mol. Psychiatry 2020, 25, 1487-1499. [CrossRef] [PubMed]

22. Kissane, D.W.; Grabsch, B.; Clarke, D.M.; Christie, G.; Clifton, D.; Gold, S.; Hill, C.; Morgan, A.; McDermott, F.; Smith, G.C. Supportive-expressive group therapy: The transformation of existential ambivalence into creative living while enhancing adherence to anti-cancer therapies. Psycho-Oncol. 2004, 13, 755-768. [CrossRef]

23. Kissane, D. Beyond the psychotherapy and survival debate: The challenge of social disparity, depression and treatment adherence in psychosocial cancer care. Psycho-Oncol. 2009, 18, 1-5. [CrossRef]

24. Zingone, A.; Brown, D.; Bowman, E.D.; Vidal, O.M.; Sage, J.; Neal, J.; Ryan, B.M. Relationship between anti-depressant use and lung cancer survival. Cancer Treat. Res. Commun. 2017, 10, 33-39. [CrossRef]

25. Ng, C.G.; Boks, M.P.; Smeets, H.M.; Zainal, N.Z.; de Wit, N.J. Prescription patterns for psychotropic drugs in cancer patients; a large population study in the Netherlands. Psycho-Oncol. 2013, 22, 762-767. [CrossRef]

26. Stiefel, F.C.; Kornblith, A.B.; Holland, J.C. Changes in the prescription patterns of psychotropic drugs for cancer patients during a 10-year period. Cancer 1990, 65, 1048-1053. [CrossRef]

27. Qaseem, A.; Kansagara, D.; Forciea, M.A.; Cooke, M.; Denberg, T.D. Management of chronic insomnia disorder in adults: A clinical practice guideline from the american college of physicians. Ann. Intern. Med. 2016, 165, 125-133. [CrossRef] [PubMed] 
28. Walsh, J.K.; Roth, T. Pharmacologic treatment of insomnia: Benzodiazepine receptor agonists. In Principles and Practices of Sleep Medicine, 5th ed.; Kryger, M.H., Roth, T., Dement, W.C., Eds.; Saunders: Glendenning, Australia, 2011; pp. $905-915$.

29. Glass, J.; Lanctot, K.L.; Herrmann, N.; Sproule, B.A.; Busto, U.E. Sedative hypnotics in older people with insomnia: Meta-analysis of risks and benefits. BMJ 2005, 331, 1169. [CrossRef]

30. Buysse, D.J. Insomnia. JAMA 2013, 309, 706-716. [CrossRef]

31. Licata, S.C.; Rowlett, J.K. Abuse and dependence liability of benzodiazepine-type drugs: GABA A receptor modulation and beyond. Pharmacol. Biochem. Behav. 2008, 90, 74-89. [CrossRef]

32. Predictable, S. Side effects of antidepressants: An overview. Cleveland Clin. J. Med. 2006, 73, 351.

33. Lovato, N.; Lack, L. Insomnia and mortality: A meta-analysis. Sleep Med. Rev. 2019, 43, 71-83. [CrossRef]

34. Wernli, K.J.; Hampton, J.M.; Trentham-Dietz, A.; Newcomb, P.A. Use of antidepressants and NSAIDs in relation to mortality in long-term breast cancer survivors. Pharmacoepidemiol. Drug Saf. 2011, 20, 131-137. [CrossRef]

35. Sundquist, J.; Ekedahl, A.; Johansson, S.-E. Sales of tranquillizers, hypnotics/sedatives and antidepressants and their relationship with underprivileged area score and mortality and suicide rates. Eur. J. Clin. Pharmacol. 1996, 51, 105-109. [CrossRef]

36. Chen, P.-L.; Lee, W.-J.; Sun, W.-Z.; Oyang, Y.-J.; Fuh, J.-L. Risk of dementia in patients with insomnia and long-term use of hypnotics: A population-based retrospective cohort study. PLoS ONE 2012, 7, e49113. [CrossRef]

37. Lee, J.; Jung, S.J.; Choi, J.-w.; Shin, A.; Lee, Y.J. Use of sedative-hypnotics and the risk of Alzheimer's dementia: A retrospective cohort study. PLoS ONE 2018, 13, e0204413. [CrossRef]

38. Andersohn, F.; Schade, R.; Suissa, S.; Garbe, E. Long-term use of antidepressants for depressive disorders and the risk of diabetes mellitus. Am. J. Psychiatry 2009, 166, 591-598. [CrossRef]

39. Kripke, D.F.; Langer, R.D.; Kline, L.E. Hypnotics' association with mortality or cancer: A matched cohort study. BMJ Open 2012, 2, e000850. [CrossRef]

40. Vincent, N.; Lionberg, C. Treatment preference and patient satisfaction in chronic insomnia. Sleep 2001, 24, 411. [CrossRef]

41. Morin, C.M.; Gaulier, B.; Barry, T.; Kowatch, R.A. Patients' acceptance of psychological and pharmacological therapies for insomnia. Sleep 1992, 15, 302. [CrossRef]

42. Mehling, W.E.; Wrubel, J.; Daubenmier, J.J.; Price, C.J.; Kerr, C.E.; Silow, T.; Gopisetty, V.; Stewart, A.L. Body Awareness: A phenomenological inquiry into the common ground of mind-body therapies. Philos. Ethics Humanit. Med. 2011, 6, 6. [CrossRef]

43. Morgan, N.; Irwin, M.R.; Chung, M.; Wang, C. The effects of mind-body therapies on the immune system: Meta-analysis. PLoS ONE 2014, 9, e100903. [CrossRef]

44. Balasubramaniam, M.; Telles, S.; Doraiswamy, P.M. Yoga on our minds: A systematic review of yoga for neuropsychiatric disorders. Front. Psychiatry 2013, 3, 117. [CrossRef]

45. Cramer, H.; Lauche, R.; Langhorst, J.; Dobos, G. Yoga for depression: A systematic review and meta-analysis. Depress. Anxiety 2013, 30, 1068-1083. [CrossRef]

46. Hofmann, S.G.; Sawyer, A.T.; Witt, A.A.; Oh, D. The effect of mindfulness-based therapy on anxiety and depression: A metaanalytic review. J. Consult. Clin. Psychol. 2010, 78, 169. [CrossRef]

47. Garland, E.L.; Brintz, C.E.; Hanley, A.W.; Roseen, E.J.; Atchley, R.M.; Gaylord, S.A.; Faurot, K.R.; Yaffe, J.; Fiander, M.; Keefe, F.J. Mind-body therapies for opioid-treated pain: A systematic review and meta-analysis. JAMA Intern. Med. 2020, 180, 91-105. [CrossRef]

48. Cherkin, D.C.; Herman, P.M. Cognitive and mind-body therapies for chronic low back pain and neck pain: Effectiveness and value. JAMA Intern. Med. 2018, 178, 556-557. [CrossRef]

49. Buffart, L.M.; van Uffelen, J.G.; Riphagen, I.I.; Brug, J.; van Mechelen, W.; Brown, W.J.; Chinapaw, M.J. Physical and psychosocial benefits of yoga in cancer patients and survivors, a systematic review and meta-analysis of randomized controlled trials. BMC Cancer 2012, 12, 559. [CrossRef] [PubMed]

50. Carlson, L.E. Distress management through mind-body therapies in oncology. JNCI Monogr. 2017, 52, 37-40. [CrossRef] [PubMed]

51. Alexander, G.; Lockwood, S. Effect of yoga on sleep quality among adult cancer patients: A systematic review. JBI Database Syst. Rev. Implement. Rep. 2014, 12, 382-419. [CrossRef]

52. Kreutz, C.; Schmidt, M.E.; Steindorf, K. Effects of physical and mind-body exercise on sleep problems during and after breast cancer treatment: A systematic review and meta-analysis. Breast Cancer Res. Treat. 2019, 176, 1-15. [CrossRef]

53. So, W.K.; Law, B.M.; Chan, D.N.; Xing, W.; Chan, C.W.; McCarthy, A.L. The Effect of Nonpharmacological Interventions on Managing Symptom Clusters Among Cancer Patients: A Systematic Review. Cancer Nurs. 2019, 43, E304-E327. [CrossRef]

54. Carlson, L.E.; Zelinski, E.; Toivonen, K.; Flynn, M.; Qureshi, M.; Piedalue, K.-A.; Grant, R. Mind-body therapies in cancer: What is the latest evidence? Curr. Oncol. Rep. 2017, 19, 67. [CrossRef] [PubMed]

55. Piet, J.; Würtzen, H.; Zachariae, R. The effect of mindfulness-based therapy on symptoms of anxiety and depression in adult cancer patients and survivors: A systematic review and meta-analysis. J. Consult. Clin. Psychol. 2012, 80, 1007. [CrossRef]

56. Zeng, Y.; Luo, T.; Xie, H.; Huang, M.; Cheng, A.S. Health benefits of qigong or tai chi for cancer patients: A systematic review and meta-analyses. Complement. Ther. Med. 2014, 22, 173-186. [CrossRef]

57. Andersen, S.R.; Würtzen, H.; Steding-Jessen, M.; Christensen, J.; Andersen, K.K.; Flyger, H.; Mitchelmore, C.; Johansen, C.; Dalton, S.O. Effect of mindfulness-based stress reduction on sleep quality: Results of a randomized trial among Danish breast cancer patients. Acta Oncol. 2013, 52, 336-344. [CrossRef] 
58. Tierney, J.F.; Stewart, L.A.; Clarke, M. Cochrane Individual Participant Data Meta-analysis Methods Group. Individual participant data. Cochrane Handb. Syst. Rev. Interv. 2019, 643-658.

59. Higgins, J.P.; Thomas, J.; Chandler, J.; Cumpston, M.; Li, T.; Page, M.J.; Welch, V.A. Cochrane Handbook for Systematic Reviews of Interventions; John Wiley \& Sons: Hoboken, NJ, USA, 2019.

60. Arroll, B.; Goodyear-Smith, F.; Crengle, S.; Gunn, J.; Kerse, N.; Fishman, T.; Falloon, K.; Hatcher, S. Validation of PHQ-2 and PHQ-9 to screen for major depression in the primary care population. Ann. Fam. Med. 2010, 8, 348-353. [CrossRef]

61. Vilagut, G.; Forero, C.G.; Barbaglia, G.; Alonso, J. Screening for depression in the general population with the Center for Epidemiologic Studies Depression (CES-D): A systematic review with meta-analysis. PLoS ONE 2016, 11, e0155431. [CrossRef]

62. Warmenhoven, F.; van Rijswijk, E.; Engels, Y.; Kan, C.; Prins, J.; Van Weel, C.; Vissers, K. The Beck Depression Inventory (BDI-II) and a single screening question as screening tools for depressive disorder in Dutch advanced cancer patients. Support. Care Cancer 2012, 20, 319-324. [CrossRef]

63. Aben, I.; Verhey, F.; Lousberg, R.; Lodder, J.; Honig, A. Validity of the beck depression inventory, hospital anxiety and depression scale, SCL-90, and hamilton depression rating scale as screening instruments for depression in stroke patients. Psychosomatics 2002, 43, 386-393. [CrossRef]

64. Wilkins, J.W.; Hamby, S.L.; Robertson, K.R.; Knorr, K.L.; Barry, N.S.; Hall, C.D. The Profile of Mood States as a screening test for major depression in HIV+ patients. Assessment 1995, 2, 181-188. [CrossRef]

65. Zigmond, A.S.; Snaith, R.P. The hospital anxiety and depression scale. Acta Psychiatr. Scand. 1983, 67, 361-370. [CrossRef] [PubMed]

66. Kroenke, K.; Yu, Z.; Wu, J.; Kean, J.; Monahan, P.O. Operating characteristics of PROMIS four-item depression and anxiety scales in primary care patients with chronic pain. Pain Med. 2014, 15, 1892-1901. [CrossRef] [PubMed]

67. Dahm, J.; Wong, D.; Ponsford, J. Validity of the Depression Anxiety Stress Scales in assessing depression and anxiety following traumatic brain injury. J. Affect. Disord. 2013, 151, 392-396. [CrossRef]

68. Sagen, U.; Vik, T.G.; Moum, T.; Mørland, T.; Finset, A.; Dammen, T. Screening for anxiety and depression after stroke: Comparison of the Hospital Anxiety and Depression Scale and the Montgomery and Åsberg Depression Rating Scale. J. Psychosom. Res. 2009, 67, 325-332. [CrossRef]

69. Beck, A.; Steer, R.; Brown, G. BDI-II, Beck Depression Inventory: Manual, 2nd ed.; Harcourt, Brace, and Company: Boston, MA, USA, 1996.

70. Plummer, F.; Manea, L.; Trepel, D.; McMillan, D. Screening for anxiety disorders with the GAD-7 and GAD-2: A systematic review and diagnostic metaanalysis. Gen. Hosp. Psychiatry 2016, 39, 24-31. [CrossRef]

71. Kummer, A.; Cardoso, F.; Teixeira, A.L. Generalized anxiety disorder and the Hamilton Anxiety Rating Scale in Parkinson's disease. Arq. Neuropsiquiatr. 2010, 68, 495-501. [CrossRef]

72. Phan, T.; Carter, O.; Adams, C.; Waterer, G.; Chung, L.P.; Hawkins, M.; Rudd, C.; Ziman, M.; Strobel, N. Discriminant validity of the Hospital Anxiety and Depression Scale, Beck Depression Inventory (II) and Beck Anxiety Inventory to confirmed clinical diagnosis of depression and anxiety in patients with chronic obstructive pulmonary disease. Chron. Respir. Dis. 2016, 13, 220-228. [CrossRef]

73. Spielberger, C.D.; Gorsuch, R.L.; Lushene, R.E. Manual for the Stait-Trait Anxiety Inventory; Consulting Psychologist Press: Palo Alto, CA, USA, 1970.

74. Higginson, C.I.; Fields, J.A.; Koller, W.C.; Tröster, A.I. Questionnaire assessment potentially overestimates anxiety in Parkinson's disease. J. Clin. Psychol. Med. Settings 2001, 8, 95-99. [CrossRef]

75. Behar, E.; Alcaine, O.; Zuellig, A.R.; Borkovec, T. Screening for generalized anxiety disorder using the Penn State Worry Questionnaire: A receiver operating characteristic analysis. J. Behav. Ther. Exp. Psychiatry 2003, 34, 25-43. [CrossRef]

76. Morin, C.M.; Belleville, G.; Bélanger, L.; Ivers, H. The Insomnia Severity Index: Psychometric indicators to detect insomnia cases and evaluate treatment response. Sleep 2011, 34, 601-608. [CrossRef]

77. Backhaus, J.; Junghanns, K.; Broocks, A.; Riemann, D.; Hohagen, F. Test-retest reliability and validity of the Pittsburgh Sleep Quality Index in primary insomnia. J. Psychosom. Res. 2002, 53, 737-740. [CrossRef]

78. Soldatos, C.R.; Dikeos, D.G.; Paparrigopoulos, T.J. The diagnostic validity of the Athens Insomnia Scale. J. Psychosom. Res. 2003, 55, 263-267. [CrossRef]

79. Spencer, J.W.; Jacobs, J.J.M.D. Complementary and Alternative Medicine: An Evidence-Based Approach, 2nd ed.; Mosby: St. Louis, MO, USA, 2003.

80. Sterne, J.A.; Savović, J.; Page, M.J.; Elbers, R.G.; Blencowe, N.S.; Boutron, I.; Cates, C.J.; Cheng, H.-Y.; Corbett, M.S.; Eldridge, S.M. RoB 2: A revised tool for assessing risk of bias in randomised trials. BMJ 2019, 366, 14898. [CrossRef]

81. Chaimani, A.; Higgins, J.P.; Mavridis, D.; Spyridonos, P.; Salanti, G. Graphical tools for network meta-analysis in STATA. PLoS ONE 2013, 8, e76654. [CrossRef]

82. Stuck, A.E.; Rubenstein, L.Z.; Wieland, D. Bias in meta-analysis detected by a simple, graphical test. Asymmetry detected in funnel plot was probably due to true heterogeneity. BMJ 1998, 316, 469. [CrossRef] [PubMed]

83. Begg, C.B.; Mazumdar, M. Operating characteristics of a rank correlation test for publication bias. Biometrics 1994, 50, $1088-1101$. [CrossRef] [PubMed]

84. Caldwell, D.M. An overview of conducting systematic reviews with network meta-analysis. Syst. Rev. 2014, 3, 1-4. [CrossRef] 